\title{
Transition from a Microfinance Institution to Regulated Bank: Technology Infrastructure Planning in a Developing Country
}

\author{
Winston Tellis and Aaron Seymour \\ Fairfield University, Fairfield, CT, USA
}

\section{Winston@mail.fairfield.edu aseymour@mail.fairfield.edu}

\begin{abstract}
In this paper, the authors describe the process of converting from a microfinance organization to a regulated bank in Haiti. The literature was helpful as far as some of the procedures were concerned, and the organization was able to use the recommendations. However the researchers found some major omissions in those recommendations as far as infrastructure was concerned. In some developing countries, it is impossible to install PCs because there is no electricity. Similarly network connections and access to the Internet without telephone service would be impossible. A comparison is made between the recommendations and the realities of the environment in Haiti. Future implementations could benefit from the findings of the authors.
\end{abstract}

\section{Introduction}

As they mature, microfinance institutions (MFI) around the world are increasingly moving towards commercial practices. The reasons for this trend are as complex as the field of microfinance itself. The main impetus appears to come from the need to leverage the savings deposits at the MFIs and turn them into funds that might be loaned to customers at competitive rates. The new source of funds would lessen dependence on foreign investors whose generosity could be diverted to other areas of concern. Many MFIs began as a social service, sometimes as part of other social services to people in disadvantaged areas. Gibbons and Meehan (June, 2000) stated, "Many [MFIs] are gradually transforming their multi-program NGOs into de facto financial institutions because microfinance has become their most effective program for poverty reduction." There is a great deal of literature on the subject of the relative success of MFIs and is not the subject of this paper. This report presents the application of one organization, Fonkoze in Haiti as it attempted to convert from MFI to regulated bank status.

Fonkoze was founded as an alternative bank for the organized poor. With headquarters located in Portau-Prince, Haiti, Fonkoze is currently in the transformation process, moving from a non-governmental organization (NGO) to a formal regulated financial organization. Fonkoze has to deal with many challenges in moving ahead with the process, one of which is the state of the infrastructure in Haiti in general, and in the cities in which it has branches, in particular. These challenges are only exacerbated by being physically located in Haiti, a developing country, where essential resources are non-existent, scarce or

Material published as part of these proceedings, either on-line or in print, is copyrighted by Informing Science. Permission to make digital or paper copy of part or all of these works for personal or classroom use is granted without fee provided that the copies are not made or distributed for profit or commercial advantage AND that copies 1) bear this notice in full and 2) give the full citation on the first page. It is permissible to abstract these works so long as credit is given. To copy in all other cases or to republish or to post on a server or to redistribute to lists requires specific permission from the publisher at Publisher@InformingScience.org unreliable. In this paper the authors review Fonkoze's transformation process and technological challenges found within this complex process, while highlighting areas where the literature is deficient. 


\section{Technology Infrastructure Planning Models}

Technology infrastructure planning models found in the literature focus primarily on management information systems (MIS). More specifically these models are categorized in two ways: (1) identifying frameworks for analysis of current software packages and (2) outlining design and implementation methodologies.

Of the two previously mentioned models, the first type of model can be seen in USAID's Management Information Systems for Microfinance: An Evaluation Framework (Mainhart, 1999). As the title suggests this document is a good source for evaluating off-the-shelf packages and existing software. The major components of the framework given are:

A) Functionality and Expandability

1) Functional completeness, appropriateness, and integration

2) Expandability and institutional growth

3) Flexibility

B) Usability

1) Ease of use and user-friendliness

2) User interface

C) Reporting

1) Reports

2) Report generation

D) Standards and Compliance

1) Accounting soundness and standards

2) Governmental and supervisory adherence

E) Administration and Support

1) Security

2) Backup and recovery

3) Fault tolerance and robustness

4) End-of-period processing

5) Support infrastructure and maintenance

6) Version control and upgrade strategy

F) Technical Specifications and Correctness

1) Technology and architecture

2) Performance

3) Number and date handling

G) Costs

1) Pricing and Costs

The evaluation framework (Mainhart, 1999) given above is helpful for evaluating software, but provides no guidance to MFIs in the developing world where branches are often spread throughout the countryside. Those offices frequently do not have the basic infrastructure critical to business operations, such as electricity and communication systems. When reviewing software it is important to match environmental conditions with the way in which the software performs. As a result, there needs to be more emphasis on infrastructure. 
From the experience of the authors of this paper we agree with Dennis Macray who says, "while [appropriate and effective hardware/software] is important, our experience in working with institutions at different levels of growth has taught us that it is crucial to pay close attention to the overall institutional capacity." (Nexus, 2000) Macray goes on to cite electricity, building security, and room temperature as examples of what needs close attention. The authors feel that this statement is confirmatory of their concern that the plans reviewed in the literature assume that there is some available infrastructure, whereas the authors have experienced regions in some countries that are totally devoid of any infrastructure. Infrastructure is a precondition that is both critical and costly, and needs to receive further attention. Even Macray, however, does little more than point out the importance of institutional capacity. He does not cite how the organizations should resolve or have resolved their infrastructure capacity problems.

The most complete and comprehensive guide on MIS for MFIs is a technical guide written by Charles Waterfield and Nick Ramsing, and published by The Consultative Group to Assist the Poorest (CGAP). The technical guide is titled Management Information Systems for Microfinance Institutions (Waterfield and Ramsing, 1998). The CGAP website provides this resource material under its technical tools series. The guide comprehensively lays out not only a framework for reviewing software packages but also addresses a development and implementation framework. The overall framework is laid out as follows:

\section{A) Introduction}

1) Why is information so important?

2) What is a management information system?

3) How do the parts of an MIS relate?

4) Need experiences with MIS be so frustrating?

5) What about manual systems or spreadsheets?

6) Can I find standard MIS software to meet my needs?

B) The Accounting System

1) Accounting systems

2) Cash versus accrual accounting

3) Fund accounting

4) The chart of accounts

5) Financial statements

C) Creating Reports

1) Defining information needs

2) Key issues in report design

3) Reporting framework

D) Tracking Performance through Indicators

1) Interpreting indicators

2) Portfolio quality indicators

3) Profitability indicators

4) Financial solvency indicators

5) Growth indicators

6) Outreach indicators

7) Productivity indicators

E) Developing and Implementing a Management Information System

1) Phase 1: Conceptualization 
Transition From A Microfinance Institution
a) Step 1: Forming the task force
b) Step 2: Defining needs
c) Step 3: Determining what is feasible
d) Step 4: Assessing the alternatives
e) Step 5: Preparing the MIS needs assessment report

2) Phase 2: Detailed assessment and design
a) Step 1: Performing a detailed assessment of software
b) Step 2: Completing the design
c) Step 3: Finalizing the MIS plan

3) Phase 3: System development and implementation
a) Step 1: Developing the software
b) Step 2: Setting up the hardware
c) Step 3: Preparing the revising document
d) Step 4: Configuring the system
e) Step 5: Testing
f) Step 6: Transferring the data
g) Step 7: Training
h) Step 8: Running parallel operations

4) Phase 4: System maintenance and MIS audit

This guide is more comprehensive than the Macray document and Fonkoze found this guide exceptionally useful. However, where Fonkoze needed to address important institutional capacity issues we found that this document provided inadequate guidance. This guide did address determining what is feasible (E.1.c.). This section breaks down feasibility into four areas (1) staff capabilities, (2) technology issues, (3) cost issues and (4) budget considerations. Within the section on technology issues the guide does address questions surrounding electricity and communication systems. However, as with other guides the section provides neither specific solutions on the topic nor does it provide a reference to other documents that can help point out how other MFIs are mitigating this problem. The remainder of this document will identify the need for further research on institutional capacity and will provide an example of how Fonkoze is resolving this issue.

Clearly, MIS is one of the most critical elements in almost any business environment. However, the literature does not provide guidance to institutions in developing countries where the infrastructure is at best weak. When the literature rightly documents the need for a well-developed MIS there appears to be an assumption that basic services such as electricity, telephone, water, and sanitation are available. The researchers found that in Haiti and perhaps other developing countries, considerable time and money must be allocated to designing and implementing the infrastructure to support the MIS modules that are critical to the operation.

\section{Fonkoze's Plan for Technology Infrastructure}

In the developed world, there are few instances where researchers have the opportunity to observe and document the process of an organization's conversion from a microfinance institution (MFI) to a regulated bank. The reason is obvious, in that microfinance is not as prevalent in the developed word as in developing countries. Recently the concept is being introduced into some inner-city areas of the U.S., but the likelihood that those institutions will need to convert to regulated status is not yet clear. 
Fonkoze (a Kreyol acronym for shoulder to shoulder) is an economic alliance of peasant organizations, women's collectives, cooperatives, credit unions, Ti Machann ("little merchants" in Kreyole) groups, and religious communities, which assists grass-roots organizations in making the transition from political to economic activity by providing financial and technical services to its members. The organization was founded in 1996 has grown to over 8,000 active borrowers with a dollar volume of 3.1 million loans and 19,500 savers with \$2.7 million dollars in total deposits by September 2001. In addition to headquarters in Port-au-Prince, Fonkoze has 17 branch offices spread throughout Haiti. This geographic dispersion creates many opportunities, but it also creates many technological challenges to a maturing financial organization. Fonkoze and other MFIs were created in response to the inability of poor people without collateral to obtain loans from regulated banks. Even subsidized institutions failed to reach low-income people, where repayment was low, and losses were high, leaving moneylenders as the only option.

As it expands its financial intermediation services to the poor, the transformation process in becoming a formal regulated financial organization is critical to Fonkoze. Fonkoze's Board of Directors has the responsibility of monitoring the mandate to serve the poor while transforming the organization to ensure future survivability. Transformation to regulated status will allow the organization to gain access to commercial sources of funding in the global market, mobilize its $\$ 2.7$ million in savings into loans, expand financial services to microentrepreneuers, and increase operational efficiencies through enhanced systems, controls, and transparency, in reporting that would result from links to regulators and other banking expertise (Champion and White, 1999).

As discussed earlier, the primary focus in the current literature regarding upgrading a microfinance institution's technology infrastructure is on MIS such as loan portfolio tracking software, general ledger accounting software, and reporting requirements (Ledgerwood, 1999, Waterfield and Ramsing, 1998, Nexus 2000, Mainhart, 1999). Clearly, MIS is one of the most critical elements in almost any business environment. However, the literature does not provide guidance to institutions in developing countries where the infrastructure is at best weak. When the literature rightly documents the need for a well-developed MIS there appears to be an assumption that basic services such as electricity, telephone, water, and sanitation are available. The researchers found that in Haiti and perhaps other developing countries, considerable time and money must be allocated to designing and implementing the infrastructure to support the MIS modules that are critical to the operation.

In fact, the Central Bank in Haiti had never received an application to convert from MFI to regulated status prior to Fonkoze's application. The initial request was denied because the Central Bank did not have the time to formulate procedures that should be followed. In a subsequent meeting, other branches of the government encouraged the Central Bank to consider the application favorably and impose conditions comparable to those on existing financial institutions in Haiti. The first requirement was the absolute need for computerized record keeping in every branch. In addition, the operations at Fonkoze and regulated banks in Haiti would have to be indistinguishable. That would require significant additional hiring, but Fonkoze had sufficient information about this aspect from the literature and from the regulatory authorities.

Fonkoze has identified five specific challenges that it faces in the transformation process. These challenges are: (1) improving loan interest yield, (2) raising required capital, (3) improving financial leadership, (4) securing legal assistance and (5) Improving data reporting. However, before Fonkoze could adequately resolve all of these challenges there were certain preconditions, which had to be met.

These preconditions to transformation include the need to ensure that the organization is sustainable (Christen, 2000). Sustainability is a precondition to obtaining a license (Christen, 2000). Sustainability, however, is a difficult precondition because it has many meanings. Sustainability could range from highly subsidized programs to fully financially self-supporting organizations and financial self-sufficiency is a prerequisite for making financial enterprises widely available to microenterprises (Otero and Rhyne, 
1994). The importance of sustainability was confirmed by Otero and Rhyne (1994) who asserted that microfinance can attain wide outreach only outside the subsidized credit model, in self-sufficient commercial institutions. MFIs historically raise their interest rates to attain sustainable levels, but cost effectiveness must also be addressed. One reason for increasing cost effectiveness is to minimize the interest rate to the poor and poorest (Gibbons and Meehan, 2000). The authors of this research report believe that in progressing through the levels of sustainability, Fonkoze must first show operational sustainability before accomplishing financial sustainability in the transformation process.

Fonkoze has met most of the requirements for operational sustainability by hiring senior staff people as required by the regulators, building institutional capacity and increasing efficiencies by upgrading its current (1) electrification management, (2) communications system and network management, (3) software acquisition and (4) hardware acquisition. Unfortunately, when Fonkoze looks to the literature for guidance it has found solutions only to problems (3) and (4).

Fonkoze is the only organization in some of the more remote areas of Haiti, and therefore the only option for the residents who wish to start a savings account. As a consequence of this activity, a significant amount of funds collected by Fonkoze cannot be used by the organization because MFIs are not permitted to invest funds from savings accounts or to loan that money to other borrowers and earn a higher interest rate. Thus in order to serve their customers better, Fonkoze applied to the Haitian Government Banking authority for permission to convert from MFI to regulated bank status.

While the government granted the organization one year to meet all the requirements, the debate within Fonkoze was more philosophical. Fonkoze was founded in 1996 as a community organization dedicated to making loans to the organized poor. Most of the members and potential customers are illiterate and without collateral have no hope of getting loans from conventional banks. Thus the work at Fonkoze is labor intensive, as each customer has to be coached and assisted through every transaction by a staff member. The Board of Directors at Fonkoze is made up of some of the members who know very well their personal dependence on the services provided by the organization. They are concerned that Fonkoze's conversion to regulated status would cause them to be separated from the organization as they have been from the regulated banks in the country. However, the Board developed policies that would protect the poor customers while greatly improving the ability of the bank to ensure its long-term survival. The funds available from the depositors' savings would be a major source of revenue once those funds were invested, would significantly improve Fonkoze's financial position.

The conversion to regulated status calls for some changes in the record keeping and database maintenance of the organization. Every branch must have a computerized record keeping system, and a centralized system at which all the transactions would be recorded on a daily basis. The authors had already reviewed some MFIs in Nicaragua, the infrastructure of which would readily support the proposed enhancements that the Haitian Banking authority was imposing on Fonkoze. However, Haiti faces many more challenges and inadequate infrastructure is certainly one of them. As previously stated, Fonkoze has 18 offices covering the entire country. Only 4 of those offices have electrical service from the local authority. Only two have telephone service, since many of the offices are in remote areas that are inaccessible to vehicles, requiring people to walk along mountain trails and ford streams as they move around. Even in areas where services existed, they were unreliable and subject to frequent interruption.

It is in this environment that the authors seek to examine the existing plans for their applicability in a developing country. What might emerge is a modified plan for developing an appropriate infrastructure in this developing country as a possible model for adoption in other such situations in developing countries. The plan is the result of the combined effort of a group of advisors from the Board of Directors, some of who have specific Information Technology of Telecommunications expertise; the Director of Information Technology for Fonkoze; an advisory group of technically qualified professionals in Haiti, and the authors. The Board of Directors must approve the plan since it involves significant capital expenditure. The 
infrastructure expense must be considered as a startup cost since without the complete implementation of such a plan, government approval would be impossible.

The following plan was developed for presentation to the full Fonkoze Board of Directors:

A. Project development - needs analysis

B. Planning and Design
i.Basic design elements
ii.Providers response to requirements definition
iii.Costs and Schedule

There are three distinct parts to the project:

1) Electrification of branch offices

2) Network and Telecommunications

3) Software acquisition

\section{A. Project Development}

The first step is to evaluate the existing situation, and then to determine the needs as far as securing government approval is concerned. The current infrastructure must be clearly defined so that the design might determine what deficiencies if any, need to be remedied. There are currently 17 branch offices and the main office in Port-au-Prince. In order to manage the project and deliver services reliably, the team decided to create three organizational levels, main office, branch office, and remote office. Clearly the remote offices are in areas that would not have the same infrastructure as the branch offices. The branch offices would act as regional service centers.

Fonkoze's main office is the only current location with computers and a staff of data recorders. All the branch offices arrange to deliver their transaction records to the main office periodically. In order to do this, an employee must use public transportation to carry the ledgers to the staff at the main office. The employee then returns to the remote branch office. This journey could take from one hour to seven hours each way depending on the distance from the capital. Only two of the branch offices have a telephone, the waiting list for a telephone where one is available could be as long as seven years. In most of the offices there is no possibility of telephone access since the terrain does not lend itself to it, and the remoteness of the land and the poverty of the people means that it would not attract service providers. Thus not only is the database lagging behind the actual activity by at least one week, it also means the branch managers are potentially making loans without knowing the true status of the customer's account.

Fonkoze currently uses software from FedComp designed to service Credit Union transactions. It is a multi-station DOS-based application, and works accurately and provides a reasonable array of report choices for the management. However, it is not a multi-currency product, and Fonkoze does a substantial business converting U.S. dollars to Haitian Gourdes. A separate version of Fedcomp had to be acquired just to handle the second currency, but that rendered the financial report exceedingly complicated and cumbersome.

Apart from the main office, four other offices had access to electricity. The Port-au-Prince branch is located within the building that houses the main office and benefits from that proximity. The other offices use either electricity from the local vendor or a diesel powered small generator to produce the electrical power they need. All the offices, including the main office, have an "inverter" or a group of batteries that store the power generated from some source for later use. Even in the capital, power is extremely erratic, and the voltage certainly fluctuates significantly. It is not unusual to have the power cut each day without 
any notice, and sometimes it does not return for several hours or even days. The telephone service is equally erratic, and that does not cover much of the country. It is not surprising then, that cellular telephones are selling well in the country. Often it is the only way for family members living in another country to contact their relatives.

Therefore unlike plans for Information Technology development in some other countries, the challenges in some developing countries such as Haiti, pose a challenge to the designer. In order to meet the requirements for regulated bank status, Fonkoze needs to make a number of infrastructure upgrades. Before planning computer and network services for Fonkoze, a plan should be developed to for the simple necessities of a business environment. Those services would include electrical and telecommunications service, and qualified and trained staff members. Obtaining adequate office space and furniture may not be as easily resolved as it would in a developed country. Just as in any other country, securing the daily money transactions and funds is a particular concern in Haiti. Some of the offices are located in structures that are inherently insecure, and the personal safety of the employees handling the funds is also a consideration. In its movement to a regulated bank, Fonkoze must take all this into account, evaluate the cost of this upgrade, the mission of the organization, and how its unique and critical service to the poor will migrate and survive in the new environment.

\section{B. Planning and Design}

i). Basic design elements: The main office should be maintained in a way that is consistent with its status as the head office of a regulated bank. It should have the appearance and support structure that inspires confidence in the customers and pride in the employees.

ii). Development of Request for Proposals (RFP): A formal RFP will be prepared so that all the respondents clearly understand the project and to what they must respond. This process also ensures a fair and analytic evaluation of each proposal.

iii). Costs and Schedule: With the RFP submissions the team will have a good idea of the potential expenses for the most expensive aspects of the technology plan. The responding vendors will also provide an execution plan that includes implementation strategy and time frame. These plans will be matched against the overall plan for the conversion to regulated status and adjusted as necessary.

The above overall plan is further divided into three specific areas of detail that are critical to the development of detailed specifications for the main office and all the other locations in the organization:

\section{Electrification of branch offices}

The objectives of this segment are a) to guarantee appropriate electrification of each branch, b) to evaluate and improve the existing installations, c) install electrical support for a two-year growth cycle, and d) put maintenance plan in place to support above current and future plans.

The above objectives would require the following items: installation of regular and backup energy systems for the computers, typically this would require an uninterrupted power supply for each system; an inverter with a digital circuit for the computers and an analog circuit for other devices; where no power currently exists, either solar cells or a diesel fired generator will be needed. The minimum requirements in every office at all levels will be electrical power for lights and fans, computers and printers, and a water cooler. The remote offices will only have a single computer, but the branches should be prepared for at least three each.

The power requirements depend on the number of electrical devices in the office. Thus the branches would require at least two inverters to ensure continuous operation even when external power supply is interrupted or unavailable. The remote offices would be able to operate with a single inverter, but a backup would be advisable. The remote offices would be backed up by the nearest regional office, where 
the state of readiness must be at the highest level at all times. The remote offices have no nearby repair facility in case of equipment failure; in fact even some of the regional offices would have to transport equipment to Port-au-Prince for repairs. Thus a plan for emergency response is essential, since in a regulated bank environment, timely reporting is a major requirement. The current inventory indicates that 5 offices (including the main office) have inverters. The remaining 12 locations have neither inverters nor electrical power supply.

The RFP respondents must provide:

- $\quad$ Itemized list of components with prices
- $\quad$ Service costs
- $\quad$ Customer expenses
- $\quad$ Form of payment
- $\quad$ Smplementation plan (Project Plan)
- $\quad$ Degular progress reports during implementation
- $\quad$ Maintenance plan

\section{Communication System and Network Design}

The objectives set up for this activity included designing and maintaining a stable, secure, and reliable environment worthy of a regulated system in any country. This must be accomplished so that the operational costs are lower, and less reliant on management intervention. The system would be independent of the existing telecommunications vendor, and designed to operate without the need to upgrade for at least three years. An important objective would be the elimination of long distance dialing through the use of alternate mechanisms. The quality of service will be indistinguishable from that of any other financial organization.

Fonkoze will address these important areas in three phases: main office, branch offices, and finally the remote offices. The main office needs all the facilities that a bank in the US would. Thus twenty-four hour telephones, network availability and access to the central database would be absolute requirements. In fact the government would not grant regulated status without that level of infrastructure. What is well known is that the cost of this infrastructure is a significant challenge to this organization as it would be to any fledgling operation in a developing country. The Board of Directors spent two years working with venture capital firms raise the investment necessary to meet the requirements of the government. The startup costs including electrification, communications, networks, and software requirements must be raised separately.

The communication between the main office and all other offices is through a telephone connection, either landlines or wireless. The branch offices will use landlines through the local telephone service to an Internet Service Provider (ISP). The remote offices will use a wireless option to connect to the ISP. A corresponding supporting network must be installed at the main office. The first phase will include the complete communications and network installation at the main office. The main office must be completely set up before the other offices can be served since the daily updates and access to the database at the central office requires that the main office be prepared for that activity. The second phase will bring the branch offices online in order of transaction volume. However, the readiness of the telephone and ISP vendors could affect the specific order of installation.

Fonkoze expects that once the entire system is operational, the reliability of their money management will improve, the information will be consistent and more accurate, and thus the service will be better at a lower cost (Appendix A). Reliance on local telephone companies is considered the weak link in the sys- 
tem. The reliability of the enterprise-wide network and communications system is dependent on service providers that have not been known for continuous service. The state of infrastructure throughout Haiti is tenuous at best even in the cities. In rural areas it is largely nonexistent. How Fonkoze expects to overcome the obstacles to continuous operation throughout its enterprise while depending on unreliable services is a significant question.

Fonkoze reviewed the options of either installing a leased line from each of the offices to the main office, or a dialup service. The first option is usually appropriate for large organizations with adequate trained staff and is both expensive, and in Haiti unreliable. The second option would not work in rural areas, where telephone service is nonexistent, and those offices that do not now have telephones would have to wait several years for a telephone connection. The technical plans call for the installation of a virtual private network (VPN) through a national ISP that will include its own telephone lines. They would include Fonkoze's main office and all the branch offices. A wireless connection will be used for offices that do not currently have a telephone and for the rural offices. A VPN is less expensive than leased lines and would eliminate all long distance dialing since each office would use a local telephone connection to the ISP. The VPN then uses the ISP's Internet service to access its central database along the secure VPN. A VPN acts as though it was a leased line although it is not. Security is effected through encryption technology and a firewall at the main office as well as the branch offices. The main office and the branch offices will have a router to connect the network segments efficiently.

The installation at the main office will include routers for the servers, and for connection to the external world, a firewall for security, software to permit remote access to the databases, and accounts with an ISP to permit every office in the system to eventually connect through the VPN along the Internet to the database system in the main office. As the system expands, every office will have connectivity to the main office. The volume of business in each office will determine the order of installation, but every office will have a VPN client. The client software permits encrypted transmission between the offices along the VPN.

\section{Banking Software Acquisition}

The present environment is not acceptable for the regulators in Haiti. The current vendor's product was acquired when Fonkoze had only one office, and 600 accounts, and a single license of the product. Within two years that license was expanded to cover 5 additional computers and one more to handle the currency conversion activity that was growing in volume. However the interface was in English and not understood by more than a few employees. In 2001 the user interface was still in DOS 6.0 and not showing signs of upgrading to a Windows environment. Clearly if Fonkoze was interested in convincing the regulators that they were prepared for regulated banking operations, a major effort would be needed in the area of software selection. At the same time the potential for a large expenditure on a software package was not lost on the Board of Directors. The Board along with the management team at the main office developed a set of objectives that could be used during the selection process.

The objectives took into account the needs of the main office and all the other Fonkoze offices in the country. The intention was to investigate the software currently being used by the regulated banks in Haiti, as well as some neighboring Caribbean countries, and decide what would be useful and desirable for Fonkoze. This exercise brought out the need for Corporate Administration, Retail Branch banking, System Administration, Operations and Control, Multiple Currency capability, and Financial Management and Reporting.

Each of the retail sites (branch offices) must include Teller and Loan operations, Financial Statements, and Profitability Analysis, Accounting, and Payroll. The Teller and Loan operations should support client identification, savings and loan groups, savings interest calculations both daily and rolled up, reimbursement schedules, certificate of deposit management, money orders, and currency exchange. Financial 
Statements, and Profitability Analysis, should include statements for savings and loan accounts, portfolio analysis, account analysis, and cash reconciliation. Accounting, and Payroll should support an integrated distributed general ledger consistent with GAAP regulations, and a complete payroll system. Thus the software would have to support multi-branch, multi currency and multi lingual operations, and have highlevel security modules, user authentication, multi-year backup and retrieval.

In all phases, there will be assessment criteria established by the Board, and by which Fonkoze will evaluate employees and the potential vendors. Every vendor would have to provide a five-year financial statement indicating the company's strength, current sales revenue, testimonials from existing customers, and any information that would allow Fonkoze to evaluate the viability of the vendor. In addition the vendor would have to supply the contact information of a current client similar to Fonkoze, and a secure address where the source code of the application would be available in case the vendor should cease to operate. The cost information should include a breakdown by software module, and should itemize training and maintenance costs clearly. Any charges in addition to the stated purchase price of the software should also be clearly itemized in the proposal.

\section{Conclusion}

The authors have presented a comparison between the process of transformation from MFI to regulated status as described in the literature and one that was implemented in a developing country. As the organization in Haiti started the process of converting to regulated status, and followed the recommended procedures, it became clear that certain critical elements were not mentioned. The absence of basic infrastructure in Haiti required significant modification to the plan. Before any software could be acquired, every office would have to be capable of supporting electrical devices, telephone services, and basic human amenities. Most designers would assume that those items were present and fail to make recommendations. The researchers found that the development of a detailed plan for electrification, and telephone communications required specific expertise. That expertise was expensive as was the equipment and projected installation cost. That new information inevitably raised the cost of conversion to regulated status, the fund raising for which was the responsibility of the Board of Directors.

The researchers believe that the problem experienced by Fonkoze in Haiti could be found in several other developing countries. In many instances even where electrical power is available, it is unreliable or inconsistent. Even telephone service in many developing countries is not very different than what was described in this report. The need for a VPN is a viable alternative to the expense and technical difficulty of creating and maintaining a private network. If not for the existence of a VPN, the only option would be for Fonkoze to create its own private network, which would raise the cost of the project considerably. The connection to the Internet through an ISP provides the security required for financial transactions, while keeping the costs down. There is usually a shortage of technically qualified personnel and Haiti certainly does not have an adequate supply of qualified technicians. By contracting with an ISP to provide a VPN, Fonkoze was freed from the responsibility to manage its own network.

It is clear that developing countries require more detailed recommendations for technology enhancement. Some of the assumptions that would be reasonable in developed countries are rendered incomplete when they are used in developing countries. Future researchers might wish to examine the particular needs of remote areas in various countries that need to share in the technological advances of the developed world or they will become victims of the digital divide.

\section{References}

Campion, A., White, V. (1999), Institutional Metamorphosis: Transformation of Microfinance NGOs, into Regulated Financial Institutions. The Microfinance Network. Occasional Paper No.4. 
Transition From A Microfinance Institution

Christen, R. (2000) Commercialization and Mission Drift: The Transformation of Latin America, Monograph, Consultative Group to Assist the Poorest. Occasional Paper No.5.

Gibbons D. Meehan, J., (2000), The Microcredit Summit's Challenge: Working Towards Institutional Financial SelfSufficiency while Maintaining a Commitment to Serving the Poorest Families. The Microcredit Summit. June 2000.

Macray, D. (2000), Safeguarding Against MISmanagment and MIStakes: Katalysis Partnership's Approach, Nexus ,(SEEP).

Mainhart, A. (1999), Management Information Systems for Microfinance: An Evaluation Framework. US Agency for International Development.

Waterfield, C., Ramsing, N. (1998), Management Information Systems for Microfinance Institutions: A Handbook, Consultative Group to Assist the Poorest, Technical Tool Series No.1.

\section{Bibliography}

Fonkoze, (2001). Report of Information Technology Subcommittee. Fonkoze. (October, 2001)

\section{Biography}

Aaron Seymour received his undergraduate Finance degree and MBA from Fairfield University. After graduation he worked at UBS/Paine Webber (formerly Swiss Bank) before returning full-time for his graduate degree. While a graduate student he became interested in the empowering aspects of microfinance. His finance training and business experience are an ideal combination for this field. He has made several trips to Central America, Haiti, and Cuba to understand first-hand the realities and cultural norms of the area. He completed a rigorous microfinance training course in Colorado in July 2001, and is now well qualified to conduct training and give advice in microfinance. He plans to spend at least one year in residence in Leon, Nicaragua and provide assistance to MFIs in the town, and develop best practices amongst the many MFIs in the region.

Winston Tellis completed his undergraduate degree in Bombay, India, and graduate studies in the U.S. Since 1965 he has been working in various positions in the computer field, both operational and managerial. He has served in various roles at Fairfield University since 1967, most recently as Acting Dean of the Dolan School of Business, prior to returning to the faculty full time. He has conducted research continuously in the intersection of IT and its impact on society. His technical background has allowed him to provide networking and software assistance to various organizations in developing countries. These efforts eventually find their way into his classroom instruction, and scholarly publications. He has published consistently in Networking, international IS, and Technology issues in developing countries. He is often found working with students at area soup kitchens, inner city high schools, and serving as a volunteer in developing countries. 


\section{Appendix A}

\section{Overall Network Architecture}

Fonkoze 2001

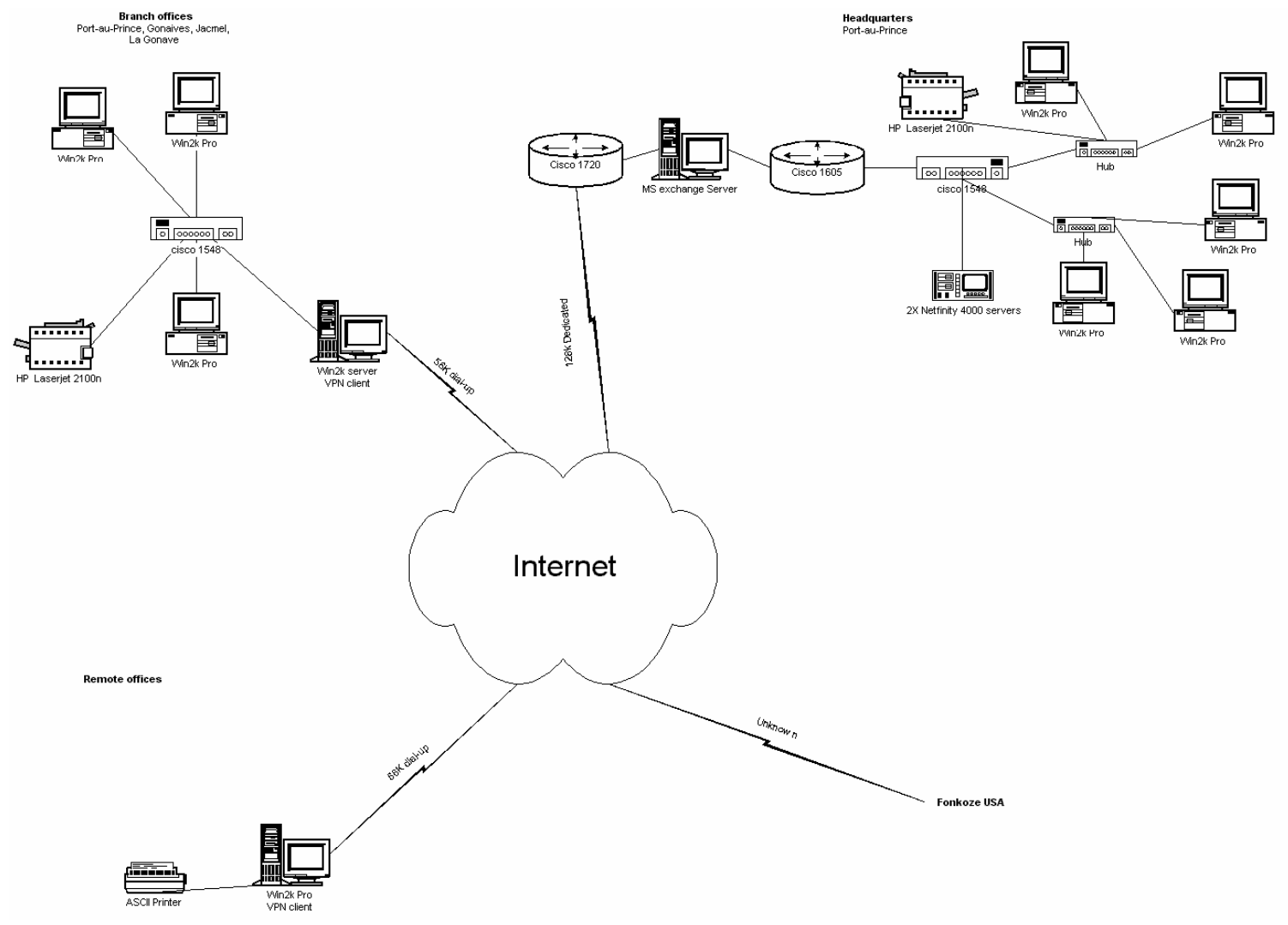

